\title{
New Methadone Formulation in France: Results from 5 Years of Utilization
}

\author{
Quentin Boucherie ${ }^{1,2}$, Elisabeth Frauger ${ }^{1,2}$, Xavier Thirion ${ }^{3}$, Michel Mallaret ${ }^{4}$ and Joëlle Micallef $f^{1,2}$ \\ 1 Aix Marseille Université, Institut de Neurosciences Timone, CNRS 7289, Service de Pharmacologie Clinique et Pharmacovigilance, \\ Marseille, France \\ 2 Centre d'Addictovigilance (CEIP), PACA-Corse Marseille, Marseille, France \\ 3 Aix Marseille Université, EA 3279 Laboratoire de Santé Publique, AP-HM, CEIP-Addictovigilance associé PACA-Corse, Marseille, \\ France \\ 4 Centre d'Addictovigilance (CEIP), CHU Laboratoire de Pharmacologie, Grenoble, France
}

Text received January $26^{\text {th }}, 2015$; accepted February $9^{\text {th }}, 2015$

\section{Keywords:}

methadone; methadone maintenance treatment; formulation; opioid maintenance treatment

\begin{abstract}
Background. In France, methadone has historically been less accessible than buprenorphine. In 2008, a dry formulation (capsule) was introduced into the market, aimed in particular to improve methadone accessibility. Objective. To describe the impact (prevalence of use, patient profiles and compliance with requirements) of the dry methadone formulation in France. Method. A retrospective cohort (from 2008 to 2012) was created from the data of the French General Health Insurance System which covers $80 \%$ of the French population. For each years, all subjects affiliated to this insurance system in southeast France (about 8.5 million inhabitants) with at least two reimbursements of methadone between $1^{\text {st }}$ January and $31^{\text {st }}$ December were selected. Results. In 2012, the proportion of capsule users was almost the same as that of syrup users $(40.0 \%$ versus $43.1 \%$; $<0.001)$. The rise in the number of methadone users has followed the rise in capsule users. Over the study period, the proportion of patients using benzodiazepines or antidepressants was 6-9\% $(\mathrm{p}<0.001)$ higher for capsule users than for syrup users. On average over the study period, $18 \%$ of subjects had at least one concurrent issue of the two forms. Conclusion. The study has shown the rapid spread of the capsule formulation among methadone users. This may suggest that the capsule is well accepted by patients and the medical community. However, the monitoring of methadone-related deaths should continue because of the pharmacodynamic properties of methadone and the context of relaxed regulations concerning access to methadone maintenance treatement (MMT).
\end{abstract}

Abbreviations: see end of article.

\section{Introduction}

Among opioid maintenance treatments (OMT), methadone is the most commonly used to treat opioid dependence, before buprenorphine. ${ }^{[1,2]}$ The conditions of access to methadone maintenance treatment (MMT) vary across countries, but are generally highly controlled because of methadone's pharmacodynamic properties. ${ }^{[3-8]}$ In Europe (European Union-27, Norway and Croatia) in 2010, methadone was used by three quarters of patients on OMT while buprenorphine was prescribed to most of the remaining patients (other substances represented less than 5\%). ${ }^{[9,10]}$

In France however, methadone has historically been less accessible than buprenorphine. In fact, three quarters of patients use buprenorphine and a quarter use methadone ( $\mathrm{n}=51384$ in 2014). ${ }^{[11]}$ MMT must be initiated by a physician in a specialized addiction care center and prescriptions should be on a special form for scheduled drugs. In addition, the duration of prescription is limited to 14 days' supply and dispensing takes place in an addiction care center or in a pharmacy. ${ }^{[5,12]}$

From 1995 to 2008 , methadone was only available in syrup form. In 2008, a dry formulation (capsule) was introduced into the market especially to improve methadone acceptability (a capsule is less stigmatizing) and thus increased its use among opioid-dependent patients. In addition, it facilitates storage in pharmacies and avoids some of the side effects of syrup (dental problems, taste...). ${ }^{[13-15]}$ The introduction of capsules was accompanied by a 
risk management plan (RMP) in order to minimize the risks associated with the use of the capsule form, such as abuse, diversion, injection, intoxication of children, overdose and black market. ${ }^{[16]}$ Therefore, legal requirements concerning the use of the methadone capsule formulation are stricter compared to the syrup formulation. Only patients who are stabilized under the syrup formulation (in medical terms and for addictive behavior) for 1 year are allowed to switch from methadone syrup to capsule form. ${ }^{[5]}$ The switch is performed at the same time and the same dose from one day to the next in a specialized addiction care centers. The aim of this study was to describe the impact (prevalence of use, patient profiles and compliance with requirements) of the dry methadone formulation in France.

\section{Materials and methods}

In France, the National Health Insurance Scheme comprises several specific regimes. Among them, the French General Health Insurance System (FGHIS) covers approximately $80 \%$ of the population residing in France, the exceptions being a few professions (students, storekeepers, farmers, self-employed, the army, the police force...). ${ }^{[1]}$ Unemployed people and those in precarious social situations are also covered by the FGHIS. In this study, information was gathered from the FGHIS reimbursement database for three French administrative areas (Provence-Alpes-Côte-d'Azur, Corsica and Rhône-Alpes) corresponding to 8.5 million inhabitants. For each year of the study (from 2008 to 2012), all subjects affiliated to the FGHIS with at least two reimbursements of methadone between $1^{\text {st }}$ January and $31^{\text {st }}$ December were selected.

The database contained information on the patient (age, gender), the prescription (prescriber identifier, date of prescription), issue (medication, date, formulation, quantity, pharmacy identifier) and other medications dispensed (during the period of methadone issue). Methadone was identified by its anatomical therapeutic and chemical code (ATC) N07BC02 as indicated by the World Health Organisation (WHO) Collaborating Centre for Drug Statistics Methodology. This code also enabled the other medications dispensed to be identified, such as opioid analgesics (ATC: N02A), antipsychotics (ATC: N05A), antidepressants (ATC: N06A) and benzodiazepines (ATC: N05BA, N05CD, N05CF, M03BX07 and N03AE01). In this study, patient, prescriber and pharmacy identifiers were sequential anonymous numbers chosen arbitrarily for each year, thus preventing any direct or indirect identification and follow-up beyond one year.

Three groups of patients were identified according to the two formulations of methadone. The syrup group $(\mathrm{Sg})$ : group of patients who had only Syrup. The capsule group $(\mathrm{Cg})$ : groups of patients who had only capsules. The syrup-capsule group ( $\mathrm{SCg}$ ): group of patients who had both formulations reimbursed in the course of the year. A descriptive and comparative analysis of the $\mathrm{Sg}$ and $\mathrm{Cg}$ groups was performed for each year (from 2008 to 2012). In the SCg, there was a focus on switches between the two forms of methadone. To study switches between methadone formulations, two pieces of information were assessed: the number of switches and the number of concurrent issues of the two forms. A switch was defined as instances where for a patient the formulation was different between two consecutive issues. However, if both forms were dispensed on the same day then the issue was considered "concurrent".

Descriptive statistics were used for the "general" profile (age, gender, number of pharmacies, physicians, number of drug issues, interval between two issues and doses issued) and the "other treatment" profile (at least one issue of another drug during the period of methadone issue). Proportions were compared using the approximate $\chi^{2}$ test, or Fisher's exact test when necessary. The t-test was applied when groups were compared in terms of continuous variables, provided that they were fairly normally distributed. MantelHaenszel linear-by-linear association chi-squared tests were performed for trend data. Post-hoc comparisons (Bonferroni method) were performed when necessary. A p-value of less than 0.05 was considered statistically significant. The statistical analysis was performed with SPSS ${ }^{\circledR}$, version 20 (IBM ${ }^{\circledR}$ SPSS Statistics, New York, USA).

\section{Results}

The evolution of the numbers of methadone users is presented in figure 1 . The proportion of syrup users among methadone users decreased significantly $(\mathrm{p}<0.001)$ between $2008(82.9 \%)$ and 2012 $(43.1 \%)$. In contrast, the prevalence of capsule users among methadone users increased significantly $(\mathrm{p}<0.001)$ between 2008 $(1.4 \%)$ and $2012(40.0 \%)$. There was no significant trend $(\mathrm{p}=0.77)$ during the study period for the proportion of $\mathrm{SCg}$.

The general profile comparison for each year between syrup users and capsule users is presented in table I and the "other treatment" profile in table II. Capsule users were older and had a higher dose per issue than syrup users. In addition, the proportions of patients with at least one benzodiazepine (BZD) or antidepressant (ATD) issue were greater in the capsule group $(+6.6 \%$ for BZD in 2012 and $+7.8 \%$ for ATD in 2012). The number of switches and the number of concurrent issues in the SCg are presented in table III. In the SC group, most patients made one switch (61.6\% in 2012) or two (17.6\% in 2012). However, some patients in the SC group did not switch (10.1\% in 2012). These were patients who had at least one concurrent issue. The proportion of patients with concurrent issues significantly increased over the study period $(+3 \%$, $\mathrm{p}<0.001$ ). For $98 \%$ of concurrent issues, both formulations were dispensed on the same day by the same pharmacist for the same prescription.

\section{Discussion}

The purpose of this work was to describe the impact (prevalence of use, patient profiles and compliance with requirements) of 


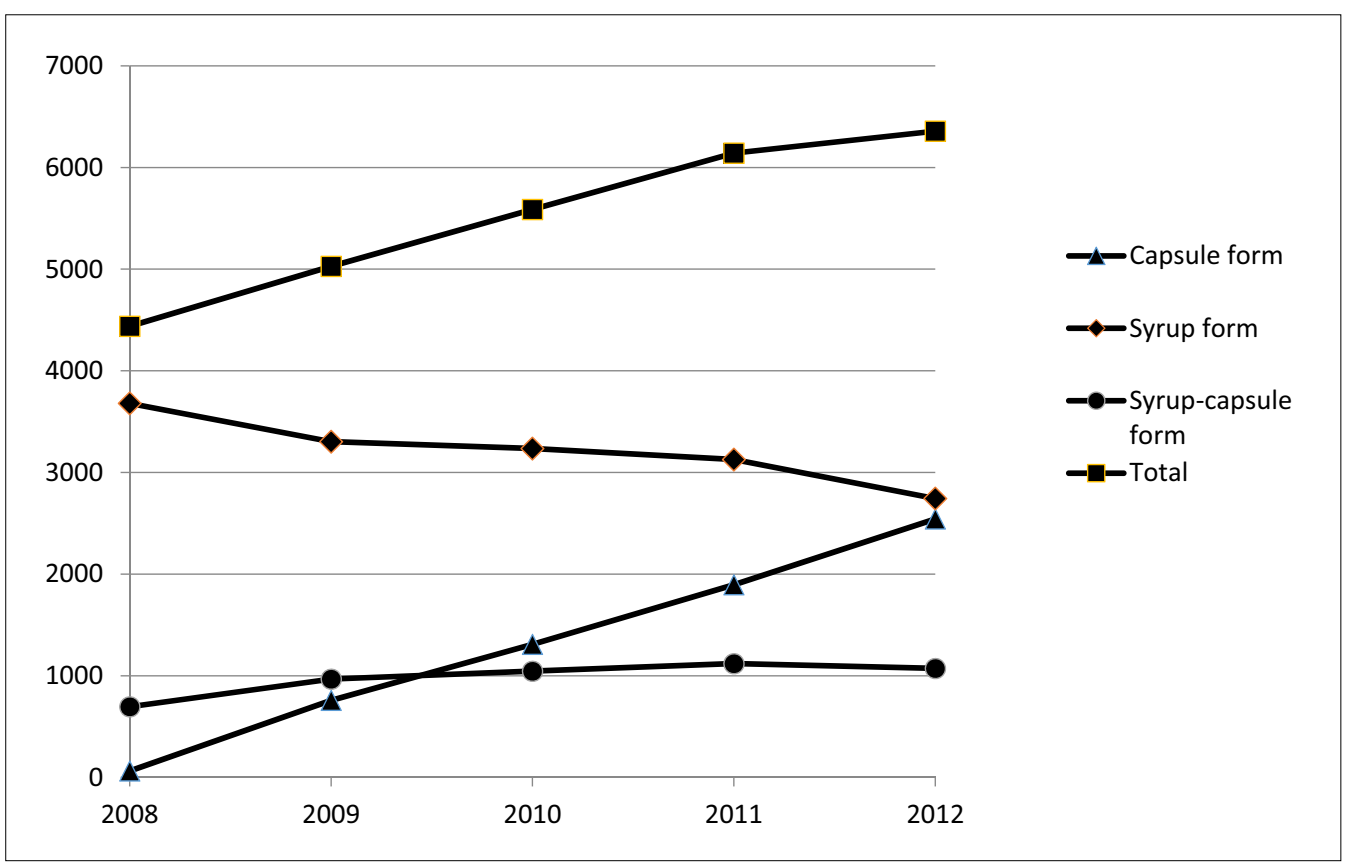

Fig. 1. Number of methadone susers based on the dosage form used between 2008 and 2012 in Provence-Alpes-Côte d'Azur, Corse and Rhône Alpes Regions.

the dry methadone formulation in France. The study shows that the number of patients using only syrup decreased considerably in five years $(-39.8 \%)$. At the same time, the number of patients on capsules increased. In fact, in 2012 the number of capsule users was almost on the same level as syrup users. The trends in figure 1 suggest that the prevalence of capsule users will exceed the prevalence of syrup users soon. This is confirmed by the sale volumes in France. ${ }^{[18,19]}$ However, access to methadone capsule formulation is subject to stricter regulations. But in spite of this, the penetration rate of the capsule form among methadone users is high.

The general profiles of patients between the two formulations are a little different (table II). Capsule users were 2 years older than syrup users, and the dose per capsule issue was $100 \mathrm{mg}$ higher than for syrup users. The difference in average age between the syrup group and the capsule group is probably attributable to the French policy of capsule prescription (only patients who are stabilized on syrup for one year can have the capsule form). ${ }^{[12,16,20]}$ The dose per issue is lower in the syrup group than in the capsule group. The differences in 2008 between these groups can be attributed to the small number of patients in capsule group. They were probably not representative of the future capsule users. Indeed, it should be noted that the capsule became available in April and thus the availability of this new form was not yet well known. The main difference between Syrup and capsule users is found in the other treatments used. The proportion of patients taking benzodiazepines or antidepressants was $6 \%$ to $9 \%$ higher in the capsule group than in the syrup group. This may be the result of better care provided to patients on capsules. ${ }^{[21]}$
Medical stabilization of opioid-dependent patients means taking care of their associated pathologies as well, such as depression, anxiety and insomnia, which are frequent in this population. ${ }^{[22,23]}$ The prescription rate of benzodiazepines in this study (51\%-61\%) is comparable to the rate in Switzerland (51\%) but rather higher than in Norway $(40 \%)$ and lower than in Germany $(73 \%) .{ }^{[24,25]}$ The prescription rate of antidepressants seems to be in line with the prevalence of depression in this population $(10-30 \%) .{ }^{[22]}$

Table III shows that most of the patients in the SC group $(61.8 \%)$ made only one switch and few of them changed methadone formulation frequently (10\% of the $\mathrm{SCg}$ ). However, some patients in the SCg made no switches at all (10.1\% in 2012; $\mathrm{n}=108$ ). These patients received only concurrent issues of the two forms. This is a rather surprising result. No clinical arguments justify the use of both formulations. The concurrent issues were related to a single physician and were not a result of "doctor shopping" or "pharmacy shopping". In fact, $98 \%$ of these prescriptions were issued by one specific physician and dispensed by one specific pharmacy. ${ }^{[26,27]}$ No study in France has reported this. However, an American study on the Researched Abuse Diversion and Addiction-Related Surveillance (RADARS) System Program reports 314 calls to Poison Centers between 2003 and 2007 (4\% of all calls) in which both liquid and tablet methadone were ingested. ${ }^{[28]}$ Several explanations are possible. The two formulations could be used by the patient, or one of them could be used by someone else, stored or even sold on the black market. This issue needs more investigation, because illegal acquisition of methadone capsules increased between 2009 and 2012 (1\% versus 3\% of 

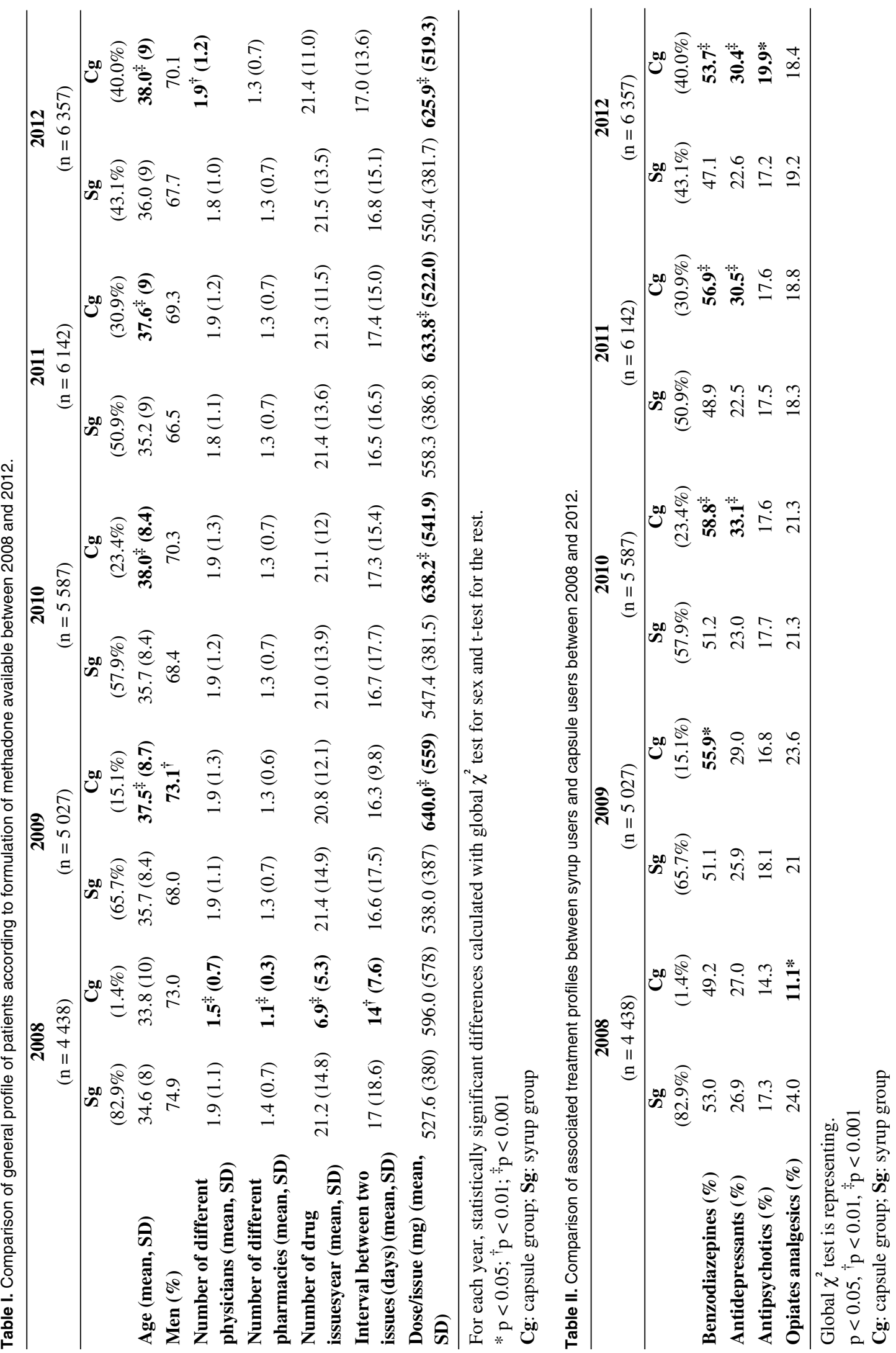
Table III. Number of switches and concomitant issue of both methadone formulations in SC group between 2008 and 2012.

\begin{tabular}{|c|c|c|c|c|c|c|}
\hline & 2008 & 2009 & 2010 & 2011 & 2012 & Trend p \\
\hline Number of patient in SC group (n): & 695 & 967 & 1044 & 1120 & 1072 & \\
\hline \multicolumn{7}{|l|}{ Number of switches (\%): } \\
\hline $\mathbf{0}$ & 4.5 & 7.5 & 11.2 & 11.4 & 10.1 & $<0.001$ \\
\hline $1(\mathrm{~S} \rightarrow \mathrm{C}$ or $\mathrm{C} \rightarrow \mathrm{S})$ & 75.3 & 63.2 & 61.8 & 60.0 & 61.6 & $<0.001$ \\
\hline $2(\mathrm{~S} \rightarrow \mathrm{C} \rightarrow \mathrm{S}$ or $\mathrm{C} \rightarrow \mathrm{S} \rightarrow \mathrm{C})$ & 10.9 & 19.2 & 17.7 & 18.8 & 17.6 & $<0.001$ \\
\hline$\geq \mathbf{3}$ & 9.4 & 10.0 & 9.7 & 9.7 & 10.7 & 0.43 \\
\hline \multicolumn{7}{|l|}{ Number of concomitant issues $(\%)$ : } \\
\hline $\mathbf{0}$ & 84.7 & 82.7 & 81.3 & 80.1 & 81.1 & $<0.001$ \\
\hline 1 & 12.9 & 13.5 & 14.3 & 16.6 & 16.0 & $<0.001$ \\
\hline$\geq 2$ & 2.4 & 3.8 & 4.4 & 3.3 & 2.9 & 0.96 \\
\hline
\end{tabular}

Trend p: Mantel-Haenszel linear-by-linear association chi-squared tests

C: methadone capsule; $\mathbf{S}$ : methadone syrup

methadone consumed). ${ }^{[29]}$ In addition, the number of methadonerelated deaths (especially in drug-naïve patients) has increased. ${ }^{[1]}$

The results of this study should be interpreted in light of some limitations. The FGHIS has a nationwide coverage but represents $80 \%$ of the French population and does not include all the different health insurance reimbursement systems. In addition, some patients do not get their treatment reimbursed systematically and/ or may obtain methadone on the street market and thus, they cannot be detected through the reimbursement database. However, they account for only a few of the patients on MMT. Indeed, in 2008, a French study reported that in $5.9 \%$ of cases, methadone was obtained illegally. ${ }^{[30]}$ Finally, methadone dispensing to patients followed in addiction care centres, and those who were hospitalized or incarcerated, are not included in the study database. Because of these limitations, our evaluation underestimates the number of switches and the number of concurrent issues of the two forms. Another limitation is that information is based on drug issues but not on the actual consumption of methadone. This is why only patients who had at least two reimbursements were included in this study. When the patient gets a second issue, it is considered that the previously dispensed methadone treatment has been used.

\section{Conclusion}

In France, methadone has been historically less accessible than buprenorphine. A dry formulation of methadone (capsule) was marketed so as to improve methadone acceptability in particular, and help to diversify the OMT offer while ensuring its safety. This study has underlined the rapid diffusion of the capsule formulation among methadone users, which may suggest good acceptability by patients and the medical community. Moreover, the profile of capsule users matched the target population defined by the French health authorities. The legal requirements for capsule formulation prescription and supply as defined by the risk management plan seem to have been complied with. However, the monitoring of methadonerelated deaths should continue, especially in a context of relaxed regulations concerning access to MMT. ${ }^{[11]}$

Acknowledgements. The authors would like to thank Dr Despina Amaslidou, Dr Vincent Sciortino (Head of the PACA CNAM-TS medical office), Dr Gilbert Weill (Head of the Rhône-Alpes CNAM-TS office), and their respective teams (Dr Véronique Allaria Lapierre and Dr François Natali from the PACA CNAMTTS office; Valérie Tainturier and Philippe Dufour from the Rhône-Alpes CNAMT-TS office )

Disclosure statement. The authors have no conflicts of interest to disclose.

Abbreviations. ATD: antidepressant; BZD: benzodiazepine; $\mathrm{Cg}$ : capsule group; FGHIS: French General Health Insurance System; MMT: methadone maintenance treatement; OMT: opioid maintenace treatements; RADARS: Research Abuse Diversion and Addiction-Related Surveillance; SCg: syrup-capsule group; WHO: World Health Organisation.

\section{References}

1. Whelan PJ, Remski K. Buprenorphine vs methadone treatment: A review of evidence in both developed and developing worlds. J Neurosci Rural Pract 2012 Jan; 3(1): 45-50

2. World Health Organization. Atlas on substance use: resources for the prevention and treatment of substance use disorders. Chapter 3: Substance-related disorders - prevention and control 2010. ISBN: 9789241500616 http://www.who.int/substance_abuse/publications/treatment/en/ Accessed February $9^{\text {th }}, 2015$

3. College of Physicians and Surgeons of Ontario. Methadone Maintenance Treatment for Opioid Dependence. Dialogue, Issue 2. Policy Statement \#210. Toronto 2010 
http://www.cpso.on.ca/uploadedFiles/policies/policies/policyitems/ methadone_maintenance.pdf

Accessed February $9^{\text {th }}, 2015$ (8 pages)

4. Dasgupta N, Davis J, Jonsson Funk M, et al. Using poison center exposure calls to predict methadone poisoning deaths. PLoS One 2012; 7: e41181

5. Haute Autorité de Santé. Methadone opinion of transparency committee. Paris 2007.

http://www.has-sante.fr/portail/upload/docs/application/pdf/2010-06/ methadone_ap-hp_ct_5198.pdf Accessed February $9^{\text {th }}, 2015$ (6 pages)

6. Nosyk B, Marsh DC, Sun H, et al. Trends in methadone maintenance treatment participation, retention, and compliance to dosing guidelines in British Columbia, Canada: 1996-2006. J Subst Abuse Treat 2010 Jul; 39(1): 22-31

7. Royal College of General Practitioners. Guidance for the use of substitute prescribing in the treatment of opioid dependence in primary care. London 2011.

http://www.rcgp.org.uk/revalidation-and-cpd/ /media/Files/SMAH/ RCGP-Guidance-for-the-use-of-substitute-prescribing-in-the-treatment-ofopioid-dependence-in-primary-care-2011.ashx Accessed February 9 $^{\text {th }}, 2015$ (48 pages)

8. Société Scientifique des Pharmaciens Francophones. La méthadone : bien prescrire, bien délivrer. E-news médecin-pharmacien 2009 http://sspf.claroline.com/claroline/backends/download.php?url=L2VuZXdzXzIwMDkvbelOaGFkb25IX19wcmVzY3JpcmVfZXRfZ OlsaXZyZXIucGRm\&cidReset=true\&cidReq=NEWS Accessed February $9^{\text {th }}, 2015$ (2 pages)

9. European Monitoring Centre for Drugs and Drug Addiction. European Drug Report. Lisbon 2013. ISSN 1977-9887 http://www.ofdt.fr/BDD/publications/docs/edr2013rap.pdf Accessed February $9^{\text {th }}, 2015$ (80 pages)

10. Riksheim M, Gossop M, Clausen T. From methadone to buprenorphine: changes during a 10 year period within a national opioid maintenance treatment programme. J Subst Abuse Treat 2014 Mar; 46(3): 291-4

11. Commission Nationale des Stupéfiants et des Psychotropes. Compte-rendu de la séance du 21 octobre 2014. Paris http://ansm.sante.fr/var/ansm_site/storage/original/application/ b6fa9fda146dc1ba87818c4f3e215e0e.pdf Accessed February $9^{\text {th }}, 2015$ (14 pages)

12. Dupouy J, Dassieu L, Bourrel R, et al. Effectiveness of drug tests in outpatients starting opioid substitution therapy. J Subst Abuse Treat 2013; 44: 515-21

13. Agence Nationale d'Accréditation et d'Évaluation en Santé. Conférence de consensus stratégies thérapeutiques pour les personnes dépendantes des opiacés : place des traitements de substitution. Paris. 2004 http://www.has-sante.fr/portail/upload/docs/application/pdf/TSO_court.pdf Accessed February $9^{\text {th }}, 2015$ (16 pages)

14. Brondani M, Park P E. Methadone and oral health--a brief review. J Dent Hyg 2011; Spring; 85(2): 92-8

15. Mysels DJ, Vosburg SK, Benga I, et al. Course of weight change during naltrexone versus methadone maintenance for opioid-dependent patients. J Opioid Manag 2011 Jan-Feb; 7(1): 47-53

16. Commission Nationale des Stupéfiants et des Psychotropes. Méthadone gélule : rapport étude observationnelle + bilan à 2 ans de commercialisation. Addendum au compte rendu du 29 avril 2010. http://ansm.sante.fr/var/ansm_site/storage/original/application/ 14f894f589f68d73eb7217ac3bdc39d3.pdf Accessed February $9^{\text {th }}, 2015$ (13 pages)
17. Tuppin $\mathrm{P}$, Neumann A, Danchin N, et al. Combined secondary prevention after hospitalization for myocardial infarction in France: analysis from a large administrative database. Arch Cardiovasc Dis 2009 Apr; 102(4): 279-92

18. Ameli. Health reimbursed national system: data on reimbursed drug from 2008 to 2011. Paris, 2012

http://www.ameli.fr/l-assurance-maladie/statistiques-et-publications/ donnees-statistiques/medicament/medic-am-2008-2012.php Accessed February $9^{\text {th }}, 2015$

19. European Monitoring Centre for Drugs and Drug Addiction. National Report 2012 (2011 data) to the EMCDDA by the Reitox National Focal Point France. New Development, Trends and in-depth information on selected issues.

http://www.emcdda.europa.eu/...cfm/att_213784_EN_Austria_NR2012.pdf Accessed February $9^{\text {th }}, 2015$ (236 pages)

20. Eiden C, Léglise Y, Bertomeu L, et al. New formulation of methadone for opioid dependence in France: acceptability and diversion/misuse liability. Therapie 2013 Mar-Apr; 68(2): 107-11

21. Eiroa-Orosa FJ, Haasen C, Verthein U, et al. Benzodiazepine use among patients in heroin-assisted $v s$. methadone maintenance treatment: findings of the German randomized controlled trial. Drug Alcohol Depend 2010 Dec 1; 112(3): 226-33

22. Peles E, Schreiber S, Naumovsky Y, et al. Depression in methadone maintenance treatment patients: rate and risk factors. J Affect Disord 2007 Apr; 99(1-3): 213-20

23. Teesson M, Havard A, Fairbairn S, et al. Depression among entrants to treatment for heroin dependence in the Australian Treatment Outcome Study (ATOS): prevalence, correlates and treatment seeking. Drug Alcohol Depend 2005 Jun 1; 78(3): 309-15

24. Bramness JG, Kornør H. Benzodiazepine prescription for patients in opioid maintenance treatment in Norway. Drug Alcohol Depend 2007 Oct 8; 90(2-3): 203-9

25. Lee HY, Li JH, Wu LT, et al. Survey of methadone-drug interactions among patients of methadone maintenance treatment program in Taiwan. Subst Abuse Treat Prev Policy 2012 Mar 20; 7: 11

26. Pradel V, Delga C, Rouby F, et al. Assessment of abuse potential of benzodiazepines from a prescription database using "doctor shopping" as an indicator. CNS Drugs 2010; 24: 611-20

27. Nordmann S, Pradel V, Lapeyre-Mestre M, et al. Doctor shopping reveals geographical variations in opioid abuse. Pain Physician 2013; 16: 89-100

28. Dasgupta N, Bailey EJ, Cicero T, et al. Post-marketing surveillance of methadone and buprenorphine in the United States. Pain Medicine 2010; 11: 1078-91

29. Commission Nationale des Stupéfiants et des Psychotropes. Compte-rendu de la séance du 20 mars 2014. Paris, 2014 http://ansm.sante.fr/var/ansm_site/storage/original/application/ 125636cafe5929ba7f654eb148fc5c07.pdf Accessed February $9^{\text {th }}, 2015$ (24 pages)

30. Frauger E, Nordmann S, Orleans V, et al. Which psychoactive prescription drugs are illegally obtained and through which ways of acquisition? About OPPIDUM survey. Fundam Clin Pharmacol 2012 Aug; 26(4): 549-56

Correspondence and offprints: Quentin Boucherie, Centre d'Addictovigilance (CEIP) PACA-Corse, Pharmacologie Médicale et Clinique, Hôpital de la Timone, CHU Marseille, 264 rue St Pierre, 13385 Marseille cedex 5, France.

E-mail: quentin.boucherie@ap-hm.fr 